\title{
Titanium-Sapphire Laser Trabeculoplasty in the Treatment of Open-Angle Glaucoma
}

\section{Modi Goldenfeld, Shlomo Melamed}

Sam Rothberg Glaucoma Center, Goldschleger Eye Institute, Sheba Medical Center, Tel Hashomer, Israel

Tel Aviv University, Sackler School of Medicine, Tel Aviv, Israel

\section{INTRODUCTION}

Laser trabeculoplasty is accepted as an effective treatment in patients with open-angle glaucoma. Success rates of 30\% IOP reduction have been reported although the effect may be temporary. ${ }^{1-4}$ There are several types of lasers currently used in glaucoma treatment including argon, diode, krypton and neodymium:YAG. ${ }^{2,5-11}$ Argon laser trabeculoplasty (ALT) is, by far, the most commonly used treatment, but may be associated with early anterior chamber reaction, local irritation, peripheral anterior synechia (PAS) formation and IOP spikes. ${ }^{6,9,11}$

Argon laser trabeculoplasty is thought to lower IOP by triggering a biological response within the trabecular meshwork (TM). However, scarring of the trabecular meshwork that is associated with ALT limits its effectiveness in subsequent applications. ${ }^{6,11-14}$ As a result of this limitation of ALT, selective laser trabeculoplasty (SLT) was developed as a gentler method of IOP reduction without the unnecessary scarring of the trabecular meshwork.

Selective laser trabeculoplasty (SLT) utilizes a frequencydoubled neodymium:YAG laser (Nd:YAG SLT) and has been shown to be at least as effective as ALT but with less ocular inflammation and fewer IOP spikes after treatment. ${ }^{1,3,15-19}$ The lack of trabecular scarring after SLT may allow repeated treatments in patients with previous ALT.

We present a third treatment option, Titanium-Sapphire laser trabeculoplasty (TiSLT) that was developed in attempt to improve the efficacy of laser therapy of the trabecular meshwork (Fig. 1).

The physical parameters of the Ti-Sapphire laser are: a wavelength of $790 \mathrm{~nm}$; exposure time of $7 \mathrm{mSec}$, and a spot size of 200 microns. (Figs 2 and 3) Such infrared wavelength is associated with deeper penetration into the TM, affecting tissues like juxta-canalicular region and inner wall of Schlemm's canal (SC) (Fig. 4). An in vivo study comparing the histology of 3 different lasers (ALT, SLT and TiSLT) in an enucleated human eye confirmed that TiSLT penetrates deeper with disruption of inner wall of Schlemm's canal (Presented at the unpublished

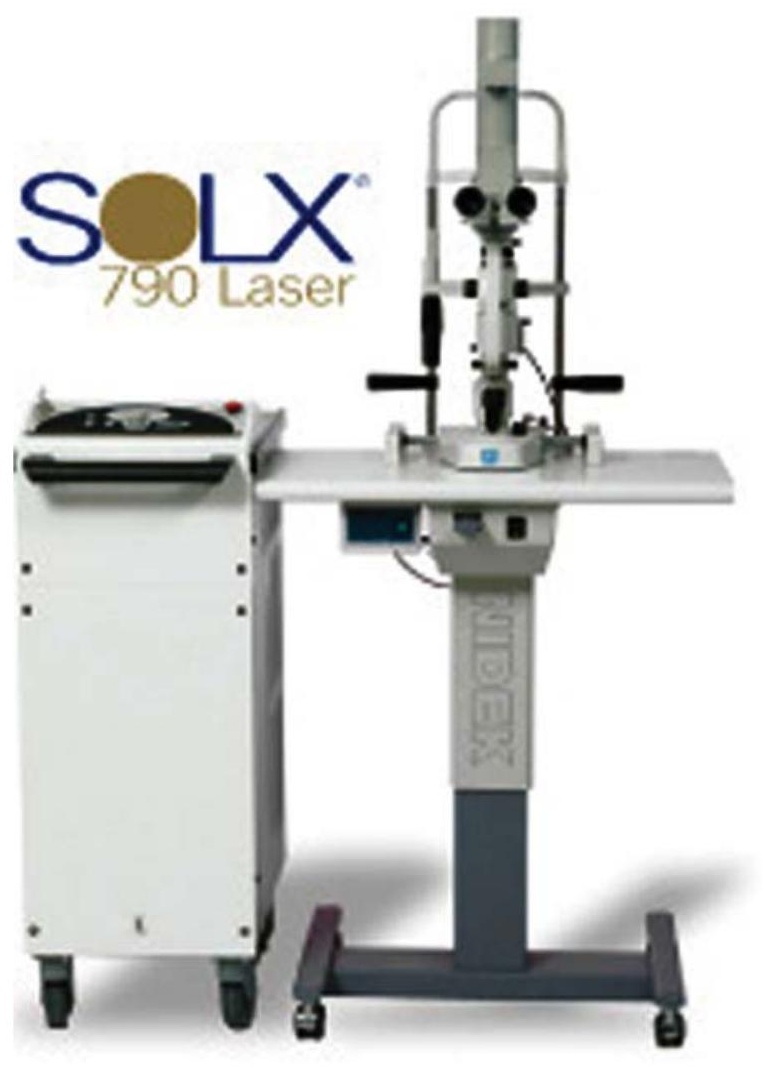

Fig. 1: SOLX 790 laser machine

data) (Figs 5 and 6). If indeed this effect occurs 'in vivo' there would be an earlier and greater reduction of IOP after TiSLT.

In the present study, we evaluate the safety and efficacy of TiSLT in patients with medically uncontrolled OAG with no previous history of filtration surgery or laser treatment.

\section{MATERIALS AND METHODS}

Eighteen patients with medically uncontrolled open-angle glaucoma were enrolled and were treated with. Mean age was 
Titanium-Sapphire Laser Trabeculoplasty in the Treatment of Open-Angle Glaucoma

\begin{tabular}{|l|l|l|l|}
\hline & \multicolumn{1}{|c|}{ ALT } & \multicolumn{1}{|c|}{ Solx 790 Laser } & \multicolumn{1}{c|}{ SLT } \\
\hline Laser type & Argon & Titanium: sapphire & $\begin{array}{l}\text { Frequency doubled } \\
\text { Q-switched Nd: YAG }\end{array}$ \\
\hline Wavelength & $\begin{array}{l}488 \text { and } 514 \mathrm{~nm} \\
\text { (blue-green) }\end{array}$ & $790 \mathrm{Nm}$ (infrared) & $532 \mathrm{Nm}$ (green) \\
\hline Energy/power per pulse & 0 to 1 watt & 30 to 80 millijoules & 0.1 to 2.0 millijoules \\
\hline Pulse duration & 0.1 to 1 second & 7 microseconds & 3 nanoseconds \\
\hline Pulse rate & Continuous wave & Single shot and $1 \mathrm{~Hz}$ & Single shot \\
\hline Spot size & 50 to 500 micron & 200 micron & 400 micron \\
\hline Peak power (max) & $2 \mathrm{~W}$ & $11 \mathrm{~kW}$ & $666 \mathrm{~kW}$ \\
\hline
\end{tabular}

Fig. 2: Comparative parameters of ALT, SLT and SOLX laser

\begin{tabular}{|l|l|l|l|}
\hline & \multicolumn{1}{|c|}{ ALT } & Solx 790 Laser & \multicolumn{1}{c|}{ SLT } \\
\hline Absorption & Strong & Moderate & Strong \\
\hline Penetration & Short & Deep & Short \\
\hline Energy & High & Moderate & Low \\
\hline Peak power & Very low & Moderate & Very high \\
\hline Pulse duration & Long & Moderate & Very short \\
\hline Thermal damage & High & Low & Low \\
\hline Repeatable & No & Yes & Yes \\
\hline
\end{tabular}

Fig. 3: Comparative parameters of ALT, SLT and SOLX laser

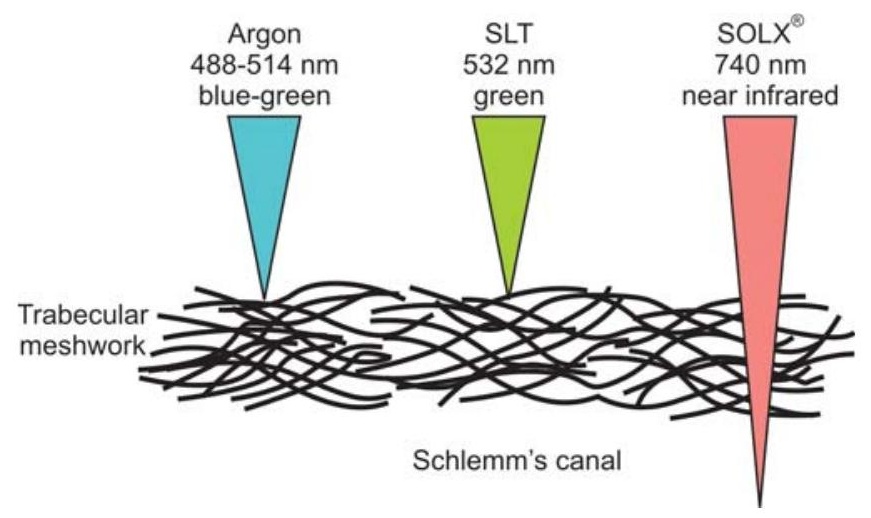

Fig. 4: Comparison of depth of penetration of the individual lasers 
SLT

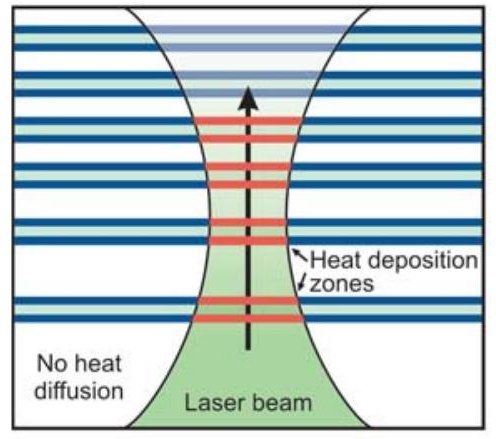

Shallow penetration low thermal effect
ALT

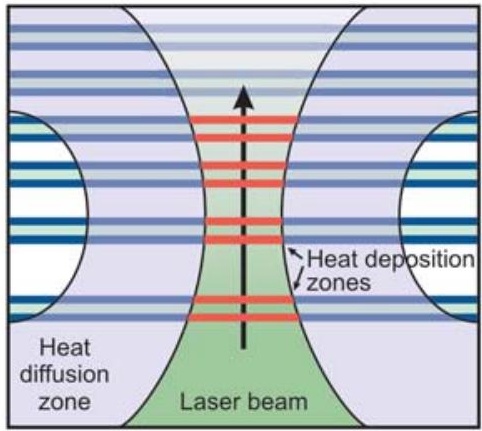

Shallow penetration wide thermal effect
SOLX

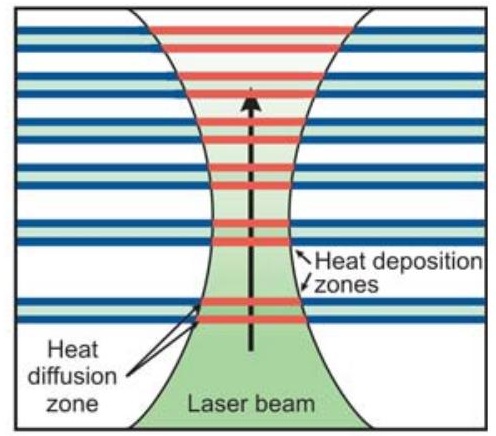

Deep penetration mid thermal effect

Fig. 5: Comparison of dissipation of laser energy of individual lasers
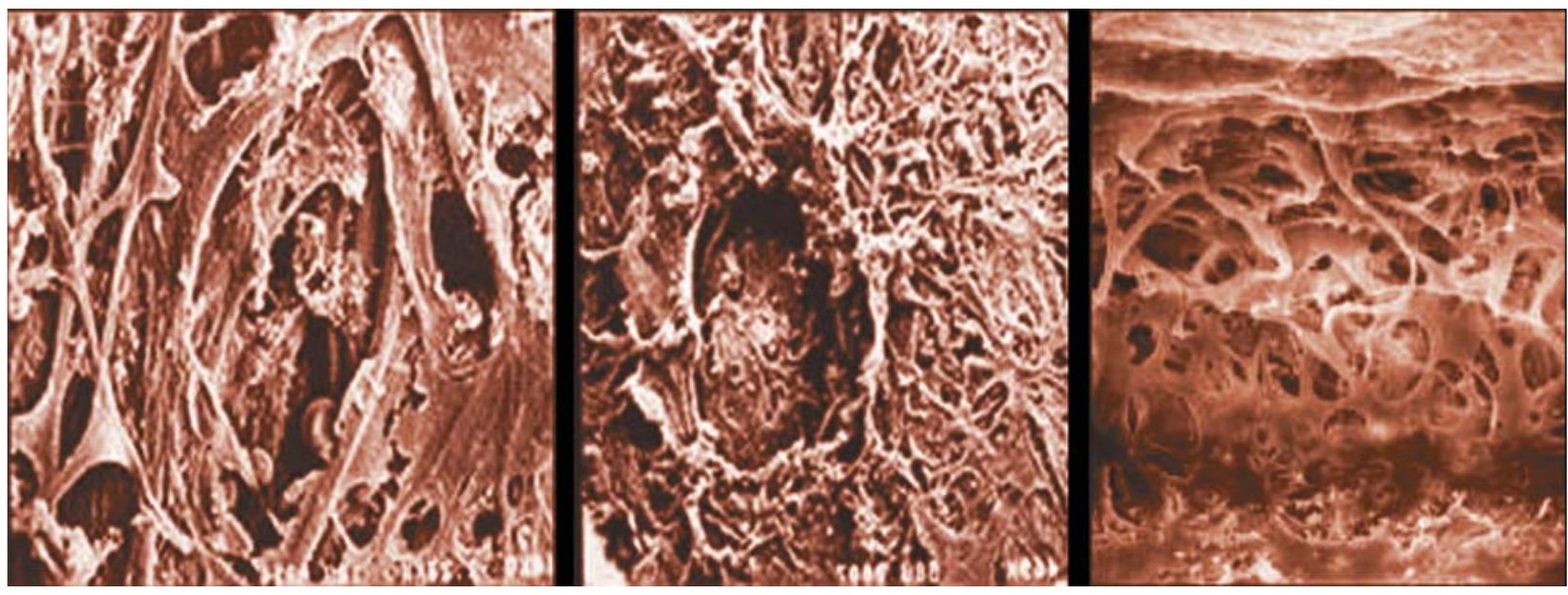

Fig. 6: Comparison of histological damage due to individual lasers

$68 \pm 11$ years [range 40-91]). The mean pre-operative IOP in the patients was $25.7( \pm 2.2) \mathrm{mmHg}$.

Patients underwent complete eye examinations including visual acuity, IOP, gonioscopy, slit-lamp biomicroscopy and visual field testing (Humphrey, 24-2, stimulus 3, Carl Zeiss AG, Oberkochen, Germany). To qualify for inclusion was a minimum IOP of $24 \mathrm{~mm}$ Hg over the course of 2 pressure checks.

Patients were examined before laser treatment and at 1 hour, 1 day, 1 week, 1 and 3 months and then every three months thereafter or as deemed necessary from their glaucoma status. Patients with follow-up of less than 3 months were excluded from the study and were considered as dropouts.

Success was defined as IOP $<=18 \mathrm{~mm} \mathrm{Hg}$ or $30 \%$ reduction in IOP without anti-glaucoma medications. In eyes where the targeted IOP was not achieved, anti-glaucoma medications were given. Patients with glaucoma progression or uncontrolled IOP, despite maximally tolerated medical management underwent trabeculectomy and were defined as failures.

\section{Laser Treatment}

TiSLT Laser treatment was performed under topical anesthesic at $180^{\circ}$ nasal of the trabecular meshwork in all cases. The patients were treated using a fixed laser setting of $790 \mathrm{~nm}$ wavelength with pulse duration of 7 microseconds and a spot size of $200 \mu \mathrm{m}$. Treatment was started with a $50 \mathrm{mj}$ spot size and was titrated down to $30 \mathrm{mj}$ if deemed necessary. A Goldman 3 -mirror goniolens was placed on the eye with $1 \%$ methylcellulose. The aiming beam was focused onto pigmented TM, and 50 adjacent, but non-overlapping laser spots were placed over $180^{\circ}$ of the TM. The endpoint of each laser application was mini-bubble or a burst of pigment. There was no use of topical apraclonidine pre-operatively or steroid eyedrops post-operatively.

IOP was assessed immediately after 1 and 2 hours, 1 day, 1 week, 1 month and every 3 months thereafter up to 18 months. 


\section{RESULTS}

The mean IOP reduction was $8.3( \pm 2.7) \mathrm{mm}$ Hg to $17.1( \pm 2.7)$ mmHg postoperatively ( $\mathrm{P}<0.001$, paired samples $t$ test). On average, there was an IOP reduction of of $32 \%( \pm 10 \%)$. The number of anti-glaucoma medications remain unchanged [1.4 $( \pm 1.0)$ pre-operatively to $1.3( \pm 1.0)$ postoperatively $(\mathrm{P}=1.0$, paired samples $t$ test)].

There was a drastic initial early post-operative drop of IOP. (Mean IOP at 2 hours post-op was $17.9 \mathrm{~mm} \mathrm{Hg}$ ).

One patient had an IOP spike (defined as an increase of IOP $>6 \mathrm{~mm} \mathrm{Hg}) 1$ hour and 2 hours post-treatment, respectively (Fig. 7).

The IOP decrease observed at 1 month was a good predictive value of the final decrease in IOP for all patients $(\mathrm{r}=0.5, \mathrm{P}=0.002$ and $\mathrm{r}=0.3, \mathrm{P}=0.7$ for 1 month and 1 week respectively).

In term of treatment failures and complications, 1 patient underwent trabeculectomy and was considered as a failure. Gonioscopy revealed an open angle without ant sign of peripheral anterior synechiae (PAS). There was no significant deterioration in visual fields at the final visit.

\section{DISCUSSION}

TiSLT was effective in this series of eyes. There was a drastic initial early post-operative drop of IOP , this early IOP reduction may suggest deeper penetration of TiSLT with disruption of inner wall of Schlemm's canal. However, this effect was short lived and IOPs had a trend to return from low teens to mid-teen levels.

Despite the efficacy of ALT, there are limitations to this procedure due to early IOP spikes (31\% according to GLT study) and PAS formation. ${ }^{6}$ Studies in monkey eyes have shown trabecular destruction followed by scarring and obstruction to aqueous flow after ALT. ${ }^{12-14}$ Such changes are the main reason for limiting ALT to 2 sessions of 180 degrees each. Too extensive ALT treatment in monkeys has been shown to trigger refractory glaucoma. ${ }^{20}$. In the current study we found no PAS formation in our glaucoma patients. This may indicate that long-term TiSLT may be safer than ALT. As far as early IOP spikes in our series, our patients had a relatively low occurrence (11\%).

Other laser techniques such as selective laser trabeculoplasty (SLT) have been shown to be safe and effective in treatment of glaucoma ${ }^{3,4,7,21}$. Previous studies comparing selective vs. argon laser trabeculoplasty in OAG patients report similar decrease in IOP ${ }^{3,4,7,21}$. Damji and associates compared SLT and ALT in OAG and found similar decreases in IOP in both groups after 1 year. ${ }^{3}$ The SLT group achieved a $5.9 \mathrm{mmHg}$ IOP decrease compared to a $6.0 \mathrm{~mm} \mathrm{Hg}$ IOP decrease in the ALT group. Similarly, both groups had a $25 \%$ reduction in pretreatment IOP at the end of follow-up. At 6 months, Martinezde-la-casa and associates report 22 and 20\% decrease in IOP in

TISLT

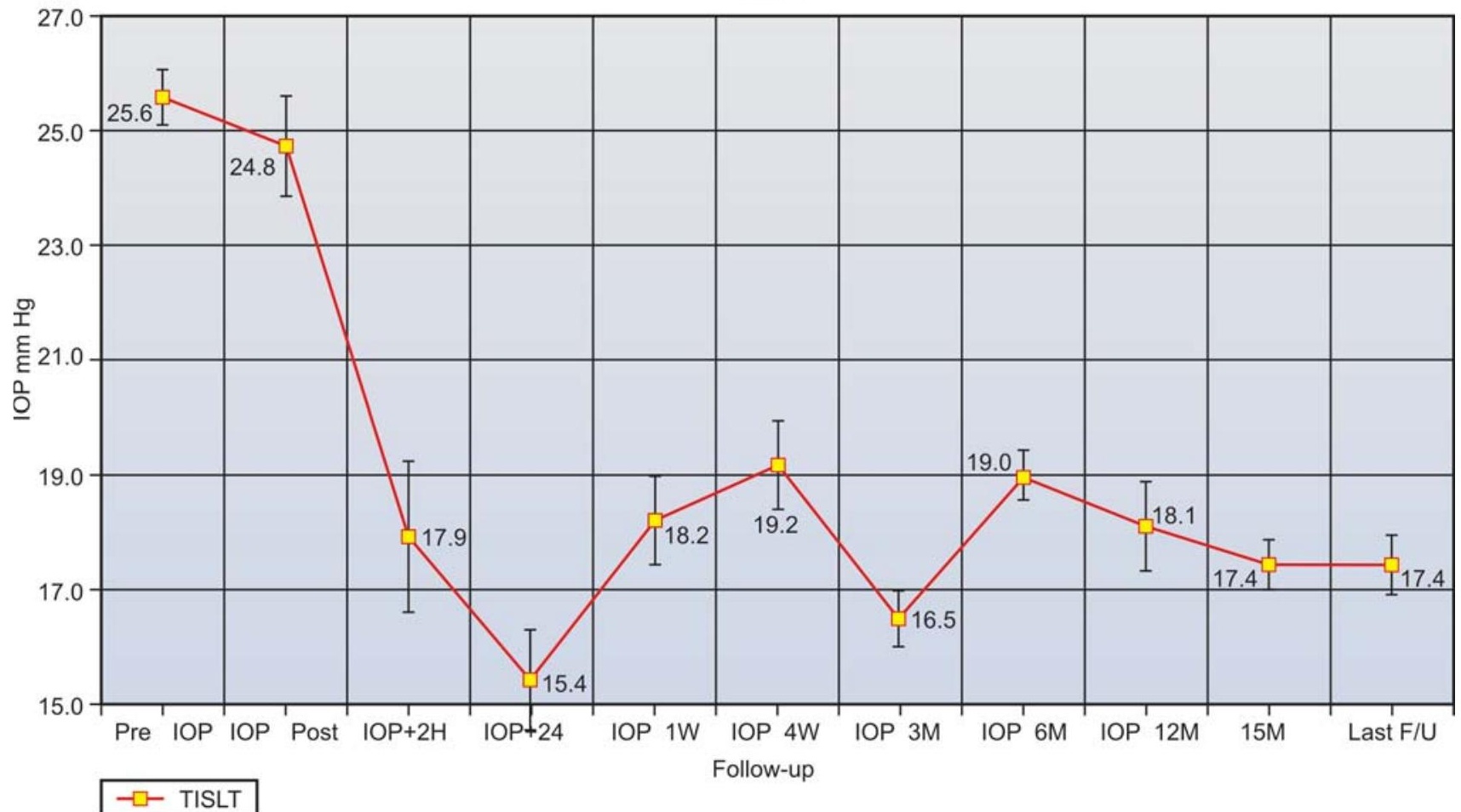

Fig. 7: Pre- and post-treatment IOP for OAG patients treated with titanium sapphire laser trabeculoplasty 
ALT and SLT groups respectively. ${ }^{4}$ Additional studies support these findings. $2,4,8,21$

We report the success of TiSLT in decreasing IOP in OAG patients over a period of 2 years; however, the majority of patients still required the same number of anti-glaucoma medication in order to control IOP.

In this preliminary study we had a relatively small number of patients . We believe that TiSLT may serve as an additional valuable tool in addition to other trabeculoplasty lasers in the reduction of IOP.

There was no PAS formation the TiSLT group may suggest a non-necrotic response in the trabecular meshwork with possible multiple re-treatments. Further studies with larger numbers of patients and longer follow-up are needed to further explore the benefits of TiSLT in the treatment of OAG.

\section{REFERENCES}

1. Melamed S, Ben Simon GJ, Levkovitch-Verbin H. Selective laser trabeculoplasty as primary treatment for open-angle glaucoma: a prospective, nonrandomized pilot study. Arch Ophthalmol. 2003: 121;957-60.

2. Damji KF, Shah KC, Rock WJ, Bains HS, Hodge WG. Selective laser trabeculoplasty v argon laser trabeculoplasty: a prospective randomised clinical trial. Br J Ophthalmol. 1999:83;718-22.

3. Damji KF, Bovell AM, Hodge WG, Rock W, Shah KC, Buhrmann R, et al. Selective laser trabeculoplasty vs. argon Laser Trabeculoplasty: Results from a One-year Randomised Clinical Trial. Br J Ophthalmol. 2006:90;1490-94.

4. Martinez-de-la-Casa JM, Garcia-Feijoo J, Castillo A, Matilla M, Macias JM, Benitez-del-Castillo JM, et al. Selective vs argon laser trabeculoplasty: hypotensive efficacy, anterior chamber inflammation, and postoperative pain. Eye. 2004:18;498-502.

5. Weinand FS, Althen, F. Long-term clinical results of selective laser trabeculoplasty in the treatment of primary open angle glaucoma. Eur J Ophthalmol. 2006:16;100-04.

6. The Glaucoma Laser Trial (GLT) and glaucoma laser trial followup study: 7. Results. Am J Ophthalmol. 1995:120;718-31.

7. de Veire S, Zeyen T, Stalmans I. Argon versus selective laser trabeculoplasty. Bull Soc Belge Ophtalmol. 2006:299;5-10.

8. Hollo G. Argon and low energy, pulsed Nd:YAG laser trabeculoplasty. A prospective, comparative clinical and morphological study. Acta Ophthalmol Scand. 1996:74;126-31.

9. Wise JB, Witter SL. Argon laser therapy for open-angle glauoma: a pilot study. Arch Ophthalmol. 1979:97;319-22.

10. Holz HA, LM. Glaucoma lasers: a review of the newer techniques. Curr Opin Ophthalmol. 2005:16;89-93.

11. The Glaucoma Laser Trial (GLT). Results of laser trabeculoplasty vs. Topical medicines. Ophthalmology. 1990:97;1403-13.
12. Melamed S, Pei J, Epstein DL. Short-term effect of argon laser trabeculoplasty in monkeys. Arch Ophthalmol. 1985:103;154652.

13. Melamed S, Pei J, Epstein DL. Delayed response to argon laser trabeculoplasty in monkeys. Morphological and morphometric analysis. Arch Ophthalmol. 1986:104;1078-83.

14. Melamed S, Epstein DL. Alterations of aqueous humour outflow following argon laser trabeculoplasty in monkeys. $\mathrm{Br} \mathrm{J}$ Ophthalmol. 1987:71;776-81.

15. Francis BA, Ianchulev T, Schofield JK, Minckler DS. Selective laser trabeculoplasty as a replacement for medical therapy in open-angle glaucoma. Am J Ophthalmol. 2005:140;524-25.

16. Latina MA, de Leon JM. Selective laser trabeculoplasty. Ophthalmol Clin J North Am. 2005:18;409-19.

17. Best UP, Domack H, Schmidt V. Long-term results after selective laser trabeculoplasty - a clinical study on 269 eyes. Klin Monatsbl Augenheilkd. 2005:222;326-31.

18. Gracner T, Pahor D, Gracner B. Efficacy of selective laser trabeculoplasty in the treatment of primary open-angle glaucoma. Klin Monatsbl Augenheilkd. 2003:220;848-52.

19. Stoiber J, Fernandez V, Lamar PD, Decker SJ, Dubovy S, Hitzl $\mathrm{W}$, et al. Trabecular meshwork alteration and intraocular pressure change following pulsed near-infrared laser trabeculoplasty in cats. Ophthalmic Surg Lasers Imaging. 2005:36;471-81.

20. Gaasterland D, Tanishima T, Kuwabara T. Axoplasmic flow during chronic experimental glaucoma. 1. Light and electron microscopic studies of the monkey optic nervehead during development of glaucomatous cupping. Invest Ophthalmol Vis Sci. 1978:17;838-46.

21. Juzych MS, Chopra V, Banitt MR, Hughes BA, Kim C, Goulas MT, et al. Comparison of long-term outcomes of selective laser trabeculoplasty versus argon laser trabeculoplasty in open-angle glaucoma. Ophthalmology. 2004:111;1853-59.

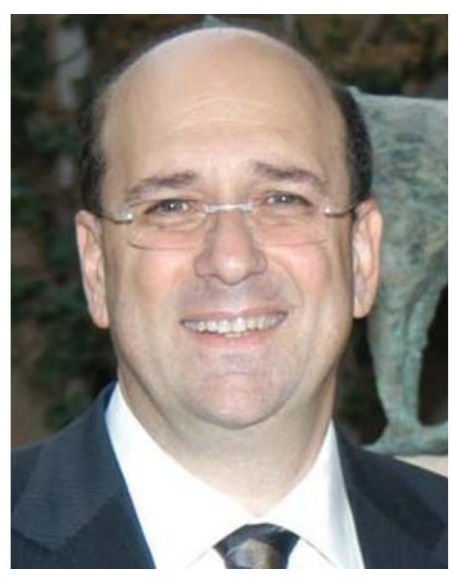

Modi Goldenfeld (modigold@ hotmail.com) 